\title{
System analysis and optimisation of a Kalina split-cycle for waste heat recovery on large marine diesel engines
}

\author{
Larsen, Ulrik; Nguyen, Tuong-Van; Knudsen, Thomas; Haglind, Fredrik
}

Published in:

Energy

Link to article, DOI:

10.1016/j.energy.2013.10.069

Publication date:

2014

Link back to DTU Orbit

Citation (APA):

Larsen, U., Nguyen, T-V., Knudsen, T., \& Haglind, F. (2014). System analysis and optimisation of a Kalina splitcycle for waste heat recovery on large marine diesel engines. Energy, 64, 484-494.

https://doi.org/10.1016/j.energy.2013.10.069

\section{General rights}

Copyright and moral rights for the publications made accessible in the public portal are retained by the authors and/or other copyright owners and it is a condition of accessing publications that users recognise and abide by the legal requirements associated with these rights.

- Users may download and print one copy of any publication from the public portal for the purpose of private study or research.

- You may not further distribute the material or use it for any profit-making activity or commercial gain

- You may freely distribute the URL identifying the publication in the public portal

If you believe that this document breaches copyright please contact us providing details, and we will remove access to the work immediately and investigate your claim. 


\title{
System analysis and optimisation of a Kalina Split-cycle for waste heat recovery on large marine diesel engines
}

\author{
Ulrik Larsen*, Tuong-Van Nguyen, Thomas Knudsen, Fredrik Haglind \\ Section of Thermal Energy, Department of Mechanical Engineering, Technical University of Denmark, \\ Building 403, Nils Koppels Allé, 2800 Kongens Lyngby, Denmark
}

\begin{abstract}
Waste heat recovery systems can produce power from heat without using fuel or emitting CO2, therefore their implementation is becoming increasingly relevant. The Kalina cycle is proposed as an efficient process for this purpose. The main reason for its high efficiency is the non-isothermal phase change characteristics of the ammonia-water working fluid. The present study investigates a unique type of Kalina process called the Split-cycle, applied to the exhaust heat recovery from large marine engines. In the Split-cycle, the working fluid concentration can be changed during the evaporation process in order to improve the match between the heat source and working fluid temperatures. We present a system analysis to identify the governing mechanisms of the process, including a comparison of the efficiency of the Split-cycle and a conventional Kalina cycle and an investigation of the effects of using reheat in both cases. Results of a multi-variable optimisation effort using a genetic algorithm suggest that the Split-cycle process can obtain a thermal efficiency of $23.2 \%$ when using reheat compared to $20.8 \%$ for a conventional reference Kalina cycle. Reheat can increase the thermal efficiency by 3.4-5.9\%. A simplified cost analysis suggests higher purchase costs as result of increased process complexity.
\end{abstract}

Keywords: Kalina Split-cycle, Process integration, Waste heat recovery, Reheat

\section{Introduction}

Waste heat recovery (WHR) systems are able to generate mechanical power and electricity without any fuel input and associated $\mathrm{CO}_{2}$ emissions. Hence, with rising fuel prices and increased environmental awareness, motivation is growing for integrating these systems to improve the energy efficiency of various processes.

The large marine diesel engine is particularly well suited to be coupled with a WHR system, whether it is applied for stationary small scale power production or for powering large ships. Although the diesel process is highly efficient, the engine looses a large part of the fuel energy to the environment, most importantly with the exhaust gasses which can contain about $25 \%$ of the input energy [1].

For large ships, the fuel expenses constitute about 30$55 \%$ of the total operational costs, depending on the type of vessel [2]. Hence, in times with high fuel prices, there are significant economic advantages associated with investing in a diesel engine exhaust WHR system [3]. The higher the fuel price, the larger investment in the WHR system can be allowed. Moreover, when considering very large ships, the large scale makes it feasible to consider relatively complex systems, compared to other WHR applications.

*Principal corresponding author. Tel.: +4553250303

Email address: ular@mek.dtu.dk (Ulrik Larsen)
Recently, Choi et al. [4] analysed the application of an advanced WHR system for a large container vessel, consisting of a trilateral cycle and an organic Rankine cycle (ORC). It was concluded that significant reductions in fuel consumption and $\mathrm{CO}_{2}$ emissions can be obtained. In general, WHR systems for combustion engines have received attention in the recent literature. Yu et al. [5] studied a combined cycle consisting of a diesel engine generator set and an ORC using the jacket cooling water and exhaust gas for additional power production. A $6 \%$ increase in thermal efficiency was predicted with the use of the ORC.

For the scale and heat source temperature level of application considered in the present work, both the ORC and the Kalina cycles have been studied using thermodynamic models. Bombarda et al. [6] compared the two processes applied for WHR on large marine engines and found that both cycles, when optimised, produced equal power outputs. Jonsson et al. [7] studied the Kalina cycle and two steam Rankine cycles in WHR systems for large diesel engines. It was predicted that the Kalina cycle can produce about $45 \%$ and $25 \%$ more power than a single and a dual pressure steam cycle. More recently, but utilising a heat source with a lower temperature, the economical performances of a Kalina cycle and an ORC were compared by Wang et al. [8]. The Kalina cycle was predicted to deliver power at a $15 \%$ lower cost than the ORC.

Research on the Kalina cycle is currently ongoing. In 


\section{Nomenclature}

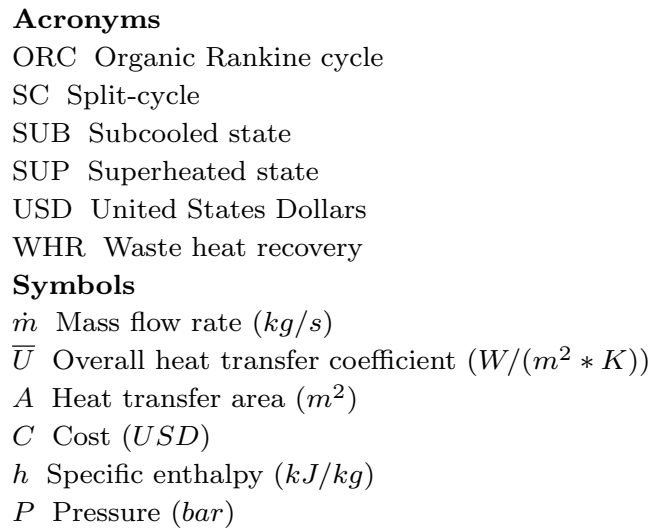

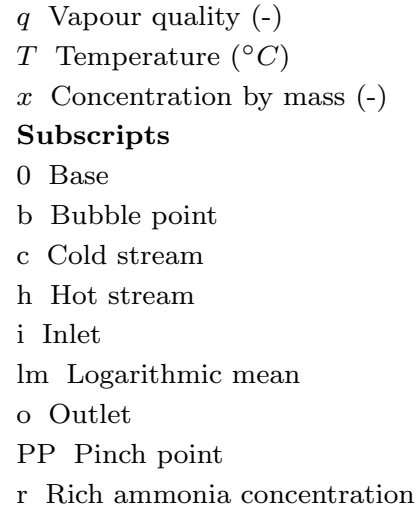

a recent study by $\mathrm{Li}$ et al. [9] it was proposed to substitute the traditional throttle valve with an ejector for improved efficiency. Wang et al. [8] optimised the thermodynamic and economical performance of a Kalina cycle using a multi-objective algorithm and presented a Pareto front useful for making decisions about the final process layout.

The main reason for the relatively high thermal efficiency of the Kalina cycle is the non-isothermal evaporation and condensation processes which occur because the working fluid is a zeotropic mixture of two fluids [10]. This enables a close matching of the temperatures of the heat source and the working fluid in the boiler, and between the heat sink and working fluid in the condenser(s). Among the many variations of the cycle, Alexander Kalina, the inventor of the Kalina cycle, has proposed a unique type of cycle layout that enables an even better match between the temperatures of the heat source and the working fluid. This is achieved by having an additional system of mixers and splitters to form two streams of working fluid with different mixture compositions that enter the boiler separately. A full description of this configuration, which Kalina named the Split-cycle (SC) [11], is provided in section 2.2.

In the literature [11], the conceptual idea of the $\mathrm{SC}$ is described, but no thermodynamic analyses or modelling efforts are presented. Previous work by the present authors [12] investigated a method for the optimisation of this special Kalina process, finding that compared to a conventional Kalina cycle the SC process may be able to improve the thermal efficiency from $20.1 \%$ to $21.5 \%$. However, the optimisation methodology was limited to including only the boiler and turbine components.

Further analyses showed that the potential of the process could not be found using this methodology, but an optimisation of the entire process is required. Due to the complexity of the process, a relatively large number of pa- rameters needs to be optimised simultaneously. Thus using a comprehensive multi-variable optimisation method is required.

This study presents, first, a system analysis with the objective of identifying the governing mechanisms of the process. Second, the potential of the Split-cycle process, in terms of conversion efficiency, is investigated in the context of the marine diesel engine WHR using a genetic algorithm optimisation methodology. The performance of a reference Kalina process is compared to the Split-cycle process, and the potential effect of implementing reheat in both cycles is studied. Third, a simplified cost analysis is presented such that the cost of the additional process complexity can be evaluated against the efficiency.

Section 2 presents descriptions of the modelled processes, while section 3 presents the methodologies of the modelling, the optimisation algorithm and the cost analysis. An analysis of the most important process mechanisms influencing the overall process efficiency is presented in section 4 along with the optimisation results and the cost analysis. Section 5 provides a brief discussion of the findings.

\section{Process descriptions}

The reference Kalina process layout and the process conditions used throughout were the same as those presented in the work of Bombarda et al. [6]. Both the reference cycle and the Split-cycle were evaluated with and without using reheat in the turbine, in order to determine the influence of this technique on the processes.

In the following, the solution concentration running through the turbine is referred to as the working solution, and the terms lean and rich refer to a low and a high concentration of ammonia in the solution. 


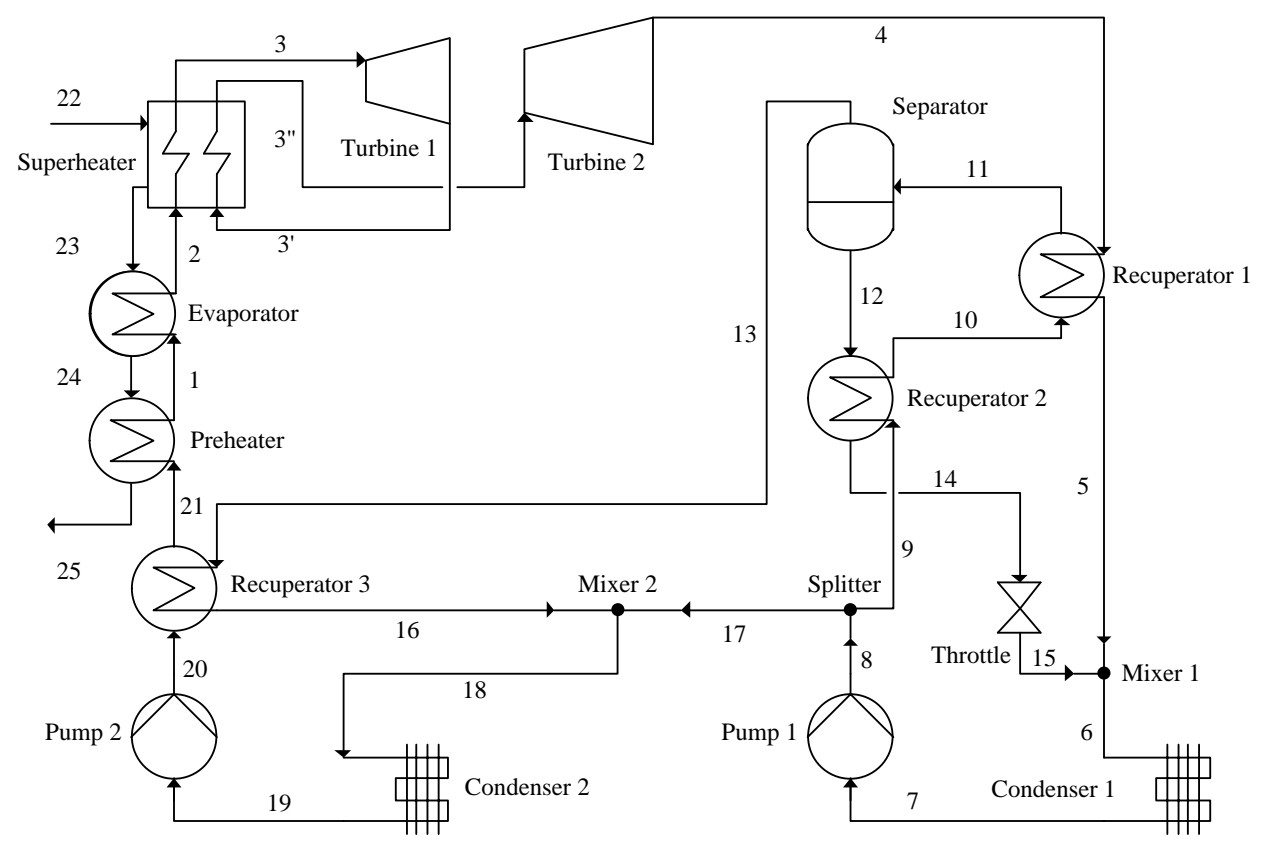

Figure 1: Sketch of the Kalina reference process with reheat

\subsection{Reference Kalina cycle}

Figure 1 illustrates the flow diagram of the reference Kalina process with reheat. Starting from (21) to (1), the preheated working fluid is evaporated and superheated in the boiler before it enters the turbine (3). In the process layout that includes the reheat technique, the outlet stream from the turbine (3') is heated in the boiler before entering (3") a second turbine. When reheat is not included in the process, stream (3) runs directly from the turbine outlet (4) to Recuperator 1. From the stream (4) heat is transferred to the stream (10) in Recuperator 1. The stream (5) is then mixed with an ammonia lean stream from the separator (15) to form a leaner solution. This solution is condensed (7) and after being pumped to an intermediate pressure level, the stream (8) is divided into two streams (9) and (17). The stream (9) is heated in Recuperator 2 and in Recuperator 1 to a partially evaporated state. It then enters the separator which separates the stream into a lean liquid (12) and a very rich vapour (13). Heat from stream (13) is used to preheat stream (20) in Recuperator 3, and the stream (16) is then mixed with a leaner solution (17) to form the working solution (18). This stream is finally condensed and pumped to the boiler pressure.

\subsection{Kalina Split-cycle}

Figure 2 illustrates the flow diagram of the Split-cycle process. To maintain focus on the special split stream boiler, the Split-cycle configuration modelled in this work was designed to have a minimum number of components needed for evaluating the concept. Hence, the SC presented here is based on the same principles as the reference Kalina cycle, with some important differences.

Two streams of different ammonia concentration enter the boiler, a rich stream (25) and a lean stream (31). Before being mixed (Mixer 4), the rich stream is fully evaporated, and the lean stream is heated to the bubble point state. The aim of this arrangement is to lower the temperatures in the overall process going from liquid $(25,31)$ to vapour (2). To be able to produce these two streams with the desired concentrations and mass flow rates, an additional mixing subsystem, is needed.

It consists of three splitters and two mixers and the three splitters divide the inlet streams (11, 12 and 18) as needed. In general, a range of combinations of the splitting fractions can provide the right flow rates and concentrations of the streams, yet there are also conditions where the streams cannot be produced as desired.

The gradient of the evaporation temperature curve can to some degree be adjusted to the temperature profile of the heat source by selecting the optimal composition of each of the two streams, as illustrated in Fig. 3. The line from $(25,31)$ to the point $\left(T_{r, b}\right)$ represents the preheat stage. From here to points (1), (2) and (3) the fully drawn line represents the heat transfer when using the Split-cycle configuration. The upper dashed line represents how the heat transfer would be if the two streams were combined into a single stream. The point $\left(T_{b}\right)$ signifies the bubble point of the combined stream, and it is clear that the temperature difference at the pinch point is much smaller and possibly violated in this case. The lower dashed line 


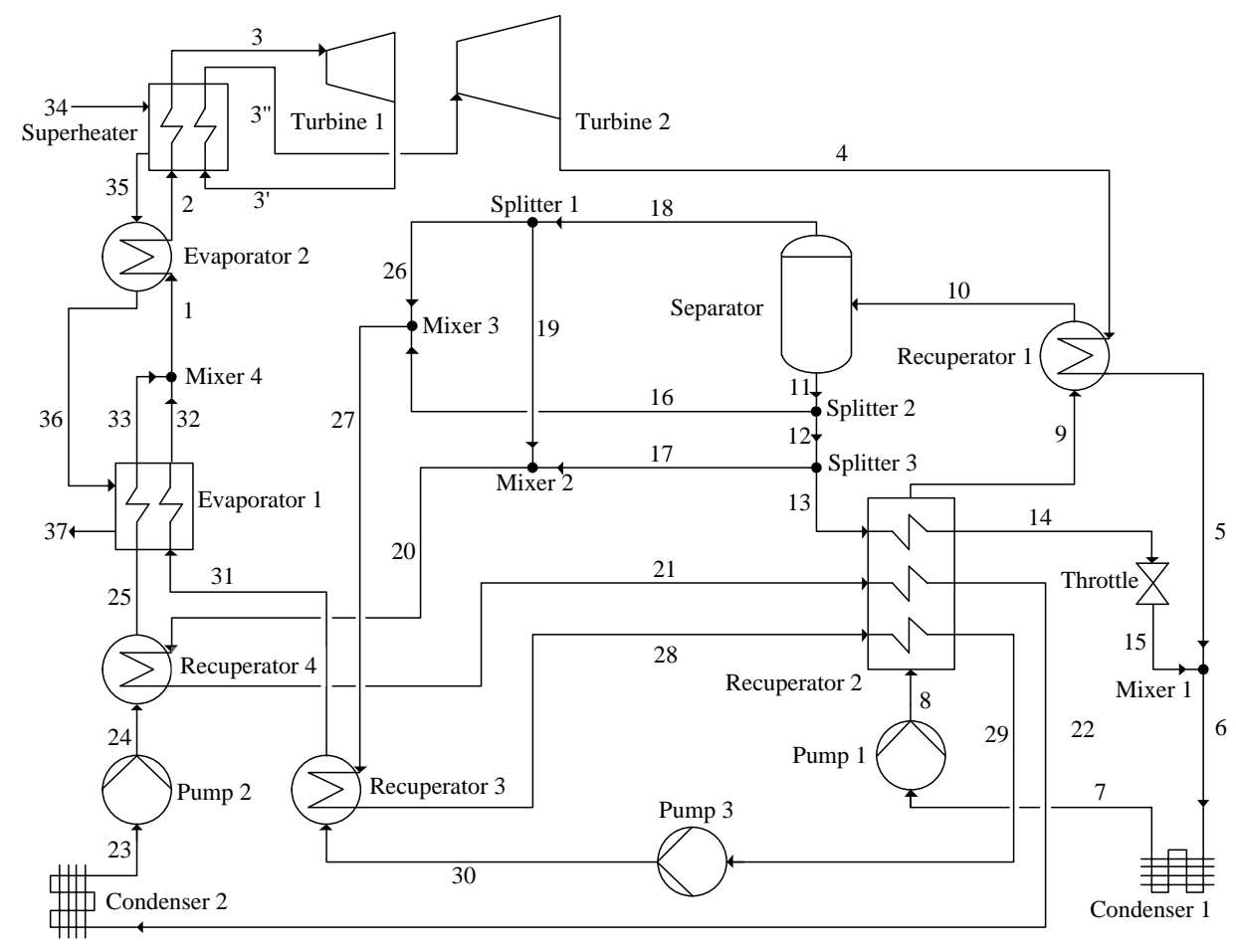

Figure 2: Sketch of the Kalina Split-cycle process

from $\left(T_{r, b}\right)$ through (2a) to (2), shows how the heat transfer would occur if only the rich stream concentration was used. Evaporation would take place at lower temperatures possibly leading to a lower thermal efficiency.

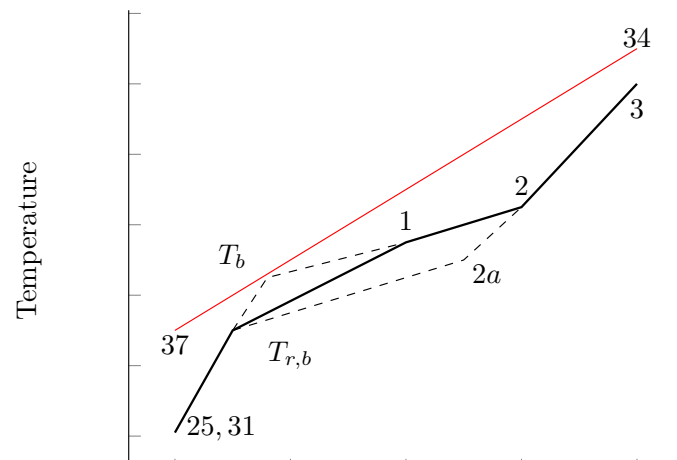

Accumulated heat transfer

Figure 3: Sketch of a Split-cycle boiler heat transfer diagram

Kalina argued [11] that the state of the rich stream at point (33) (Fig. 2) should ideally be at the dew point and that the lean stream at point (32) should be at the bubble point, before the mixing of the two streams. The two streams should also have similar temperatures and pressures in order to minimise the entropy generation in this section of the boiler. We decided to adopt these constraints without further analysis to focus on the full process analysis. However, an entropy generation analysis is planned for future work to verify this claim. In the following, these conditions are referred to as the SC boiler constraints.

A direct consequence of the SC boiler constraints is that, once the ammonia concentration of one of the streams, (25) or (31), has been chosen, the concentration of the other is fixed in order to satisfy the equilibrium conditions. Additionally, when the boiler pressure and the concentration in one stream are chosen, the temperature of the working fluid streams out of evaporator 1 is fixed. Both are illustrated in the example shown in Fig. 4. As shown, the mixing temperature decreases and the lean stream concentration increases, as the rich stream concentration increases.

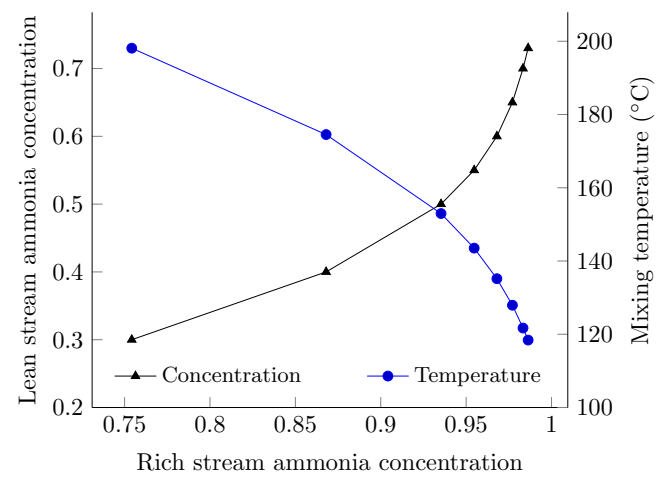

Figure 4: Equilibrium conditions for Evaporator 1 outlet 
Table 1: Process parameters and conditions

Heat source inlet temperature $\left({ }^{\circ} \mathrm{C}\right) \quad 346$ Heat source outlet temperature $\left({ }^{\circ} \mathrm{C}\right) \quad 127.7$ Turbine polytropic efficiency $(\%) \quad 70.5$ Turbine mechanical efficiency (\%) 96 Pump isentropic efficiency (\%) 70 Pump mechanical efficiency (\%) 95 $\Delta T_{P P}$ evaporators $\left({ }^{\circ} \mathrm{C}\right) \quad 21.9$ Superheater approach $\left({ }^{\circ} \mathrm{C}\right) \quad 16$ $\Delta T_{P P}$ recuperators $\left({ }^{\circ} \mathrm{C}\right)$ Cooling water inlet temperature $\left({ }^{\circ} \mathrm{C}\right) \quad 25$ $\Delta T_{P P}$ condenser $\left({ }^{\circ} \mathrm{C}\right) \quad 5.0$

\section{Methodology}

This section describes the models and conditions used as well as the optimisation and cost estimation methodologies. In previous work [12] the authors derived a preliminary optimisation methodology for the Split-cycle process. Subsequent work demonstrated that a need for a more comprehensive approach exists, mainly because of the strong influence of the turbine exhaust pressure on the process net power output; therefore the previous methodology and models were further developed to include the entire Split-cycle process.

\subsection{General modelling conditions}

Table 1 presents the process parameters common for all simulations. The heat source data was adopted from Bombarda et al. [6] being an exhaust gas stream from two marine diesel engines, with the molar composition $74.6 \%$ $\mathrm{N}_{2}, 11.7 \% \mathrm{O}_{2}, 6.7 \% \mathrm{H}_{2} \mathrm{O}, 5.9 \% \mathrm{CO}_{2}$ and $1.1 \% \mathrm{Ar}$ and $\mathrm{a}$ total mass flow rate of $35 \mathrm{~kg} / \mathrm{s}$.

Pressure and heat losses were neglected in the models, to investigate the full potential of the cycles. All flows were considered homogeneous in terms of temperature, pressure and solution concentration, and the models were developed for steady-state conditions.

It was assumed for the optimisation cases that the feasible upper limit for the high pressure of the processes is 130 bar to avoid supercritical pressures and possibly excessive costs. The risk of sulphuric acid condensation in the boiler limits the minimum exhaust gas temperature when the fuel contains sulphur. The value of $127.7^{\circ} \mathrm{C}$ was chosen to be able to compare results with the results of Bombarda et al. [6] on an even basis. While providing higher thermal efficiencies, all optimisation efforts with higher exhaust temperatures resulted in lower power outputs. The discharge temperature was therefore kept fixed at $127.7^{\circ} \mathrm{C}$ in all cases.

\subsection{Subsystem models}

The preliminary optimisation methodology was based on the SC boiler constraints. Two subsystem models were made using MATLAB ${ }^{\circledR}$ version 2010b [13] with thermodynamic properties obtained using NIST Refprop version 9 [14]. The equation of state applied in Refprop for ammoniawater mixtures is a model derived by Tillner-Roth and Friend [15] and is among the most accurate available [16].

\subsubsection{Boiler and turbine model}

The boiler consists of two evaporators, a mixer and a superheater (with reheater). In order to find the minimum allowed temperature difference $\left(\Delta T_{P P}\right)$ and prevent violation of the second law of thermodynamics in the boiler, each heat exchanger was discretised into 20 parts with equal temperature steps, a number that was found to provide sufficient accuracy while being computationally efficient. This approach is useful because the evaporation process is non-isothermal and the location of the pinch point may not be easily predicted when varying the parameters during the optimisation.

The heat source inlet and outlet temperatures and pressure were kept as constant. The working fluid turbine inlet temperature was also kept as constant, allowing the boiler pinch point temperature difference and working fluid mass flow rate to be determined. The working fluid boiler inlet temperature and the boiler pressure were variables set by the optimisation algorithm.

The turbine was modelled using a constant polytropic efficiency in order to ensure a comparable level of technology, while investigating a wide range of boiler pressures. The polytropic efficiency was determined such to produce the same isentropic efficiency as was used in the work of Bombarda et al. [6], in order to compare the works on an even basis.

\subsubsection{Mixing system model}

The mixing system consists of a separator, three splitters and two mixers. By modelling these components and using as inputs the compositions of the streams (25) and (31) found from the boiler model, we calculated the mass flow fractions of the three splitters and separator feed mass flow rate (10). Temperature, pressure and solution concentration of the separator feed stream as well as the working solution concentration were inputs for the mixing system model provided by the optimisation algorithm. The separator was modelled using the equation of state to find the vapour and liquid equilibrium concentrations of the twophase mixture feed. We used mass balance equations to determine the separator outlet mass flow rates (18) and (11) and also to determine the mass flow rate fractions of the splitters.

\subsection{Full process model}

The two mentioned subsystem models were used as a basis for a full process model. The remaining components in the full process model were modelled similarly as described in section 3.2 .

All recuperators were modelled using a suitable number of steps between inlet and outlet. This was done because the recuperator streams in the process are mixtures of two fluids which change phase non-isothermally, hence the location of the pinch point is not known beforehand. The pumps were modelled using an isentropic efficiency instead of a polytropic efficiency in order to reduce the computational time. 


\begin{tabular}{rr} 
Table 2: Genetic algorithm parameters \\
\hline Generations & 30 \\
Sub-populations & 4 \\
Individuals & $100-200$ \\
Cross-over rate & 1 \\
Generation gap & 0.8 \\
Mutation rate & 0.5 \\
Insertion rate & 0.9 \\
Migration rate & 0.2 \\
Generations between migration & 2
\end{tabular}

The full system model was also made in MATLAB ${ }^{\circledR}$ and verification of the results of the equation system was made using the commercial process simulation software Aspen Plus ${ }^{\circledR}$ version 7.2 [17]. These verification simulations were also conducted using the Refprop equations of state.

\subsection{Optimisation}

We used a genetic algorithm [18] to perform a multivariable optimisation. Between seven and nine variables were optimised simultaneously by the algorithm. The algorithm works by emulating the optimisation parameters as if they were genes of an individual. A number of individuals comprise a population, and the performance of an individual determines whether its genes will be part of subsequent generations of individuals. The performance is evaluated by the net power output from using the genes (parameters) as inputs to the process models. Since the heat source discharge temperature is kept constant, it is in the present cases equivalent to optimising for thermal efficiency, as defined by the ratio of the net power output to the heat input. The first generation of individuals is produced stochastically, but the next generations are based on the genes of the fittest individuals of previous generations. As in nature, random mutation of the genes is emulated as well as cross-over of genes. After a number of generations, the best possible combination of parameters can be obtained.

The optimisations were done using the MATLAB ${ }^{\circledR}$ GA-toolbox which is part of the Global Optimization Toolbox. This method was chosen for the following reasons: 1) The optimisation algorithm does not need derivatives, 2) It is designed to optimise a relatively large number of variables, 3) It is designed to find the global optimum in a solution domain which has many local optima, by using many parallel optimisations, which in the present cases are 400-800.

The present study uses the chosen genetic algorithm parameters based on experiences, with the process model and algorithm; see Table 2. Table 3 lists the ranges allowed for the optimisation parameters. The boiler approach here refers to the minimum temperature difference between the hot and cold streams in the recuperator which preheats the stream(s) before entering the boiler. The working fluid boiler inlet temperature is therefore equal to the separator feed temperature minus the boiler approach.

\subsection{Cost analysis}

For the purpose of evaluating the additional cost resulting from an increased process complexity, a simplified equipment purchase cost estimation of the studied cycle configurations was made, using the methodology described by Rodriguez et al. [19]. No operational and maintenance expenses have been considered in the analysis under the assumption that the purchase cost is the largest contributor to the total expenses, and that the marginal differences between the operational and maintenance costs in each of the cases are negligible. The heat transfer areas were estimated using the following correlation:

$$
A=\frac{\dot{Q}}{\bar{U} * \Delta T_{l m}}
$$

where $\bar{U}$ is the heat exchanger overall heat transfer coefficient, $\dot{Q}$ is the heat transfer rate, $A$ is the heat transfer area and $\Delta T_{l m}$ is the logarithmic mean temperature difference:

$$
\Delta T_{l m}=\frac{T_{h, i}-T_{c, o}-\left(T_{h, o}-T_{c, i}\right)}{\ln \left(\left(T_{h, i}-T_{c, o}\right) /\left(T_{h, o}-T_{c, i}\right)\right)}
$$

Subscripts h, c, i and o denotes hot and cold streams at inlets and outlets. Since the above equation assumes a linear heat transfer/temperature profile, it is, for zeotropic mixture fluids, necessary to discretise the heat exchangers into a number of steps (here 20).

The assumed overall heat transfer coefficients are shown in Table 6 (Section 4). For the condensers, the $\bar{U}$ values were adopted from Rodriguez et al. [19], who modelled and analysed a low temperature Kalina cycle. However, since the heat source is hot water in the case of Rodriguez et al., the $\bar{U}$ values for the boiler components were derived by combining the information in two studies by Thorin et al. [20, 21], who analysed the heat transfer areas of a similar Kalina cycle utilising exhaust gas.

The $\bar{U}$ values for each of the recuperators are unique because the phases on each side of the heat exchanger are different in each recuperator. In the present cycles all combinations occur: liquid/liquid, two-phase/liquid, twophase/gas, two-phase/two-phase and gas/liquid. However, to simplify the analysis, an average value based on the values derived from Thorin et al. [20, 21], was used. All the heat exchangers are assumed to be of the shell and tube type.

The overall heat transfer coefficients are in practice highly dependent on heat exchanger geometries and materials, and the fluid flow conditions. It is a comprehensive task to predict these values accurately and furthermore, the currently available transport property models and heat exchanger coefficient models for ammonia-water mixtures may not be very accurate [21]. Therefore, the results can only be used as a first approximation of the heat transfer areas. 


\begin{tabular}{rr} 
Table 3: Parameter limits \\
\hline Separator feed temperature $\left({ }^{\circ} \mathrm{C}\right)$ & $75-125$ \\
Separator feed pressure (bar) & $6-14$ \\
Separator feed concentration (by mass) & $0.30-0.70$ \\
Working solution concentration (by mass) & $0.55-0.85$ \\
Turbine outlet pressure (bar) & $2-7$ \\
Reheat pressure (bar) & $20-60$ \\
Turbine inlet pressure (bar) & $50-130$ \\
Boiler approach ( $\left.{ }^{\circ} \mathrm{C}\right)$ & $5-50$ \\
Rich stream concentration (by mass) & $0.60-0.96$ \\
\hline
\end{tabular}

The base cost $\left(C_{0}\right)$ for the components, also adopted from Rodriguez et al. [22], are 4405 United States Dollars (USD) per $\mathrm{kW}$ for the turbines, $1120 \mathrm{USD} / \mathrm{kW}$ for the pumps and $588 \mathrm{USD} / \mathrm{m}^{2}$ for the heat exchangers. The cost $(C)$ of the turbines $(t)$, pumps $(p)$ and heat exchangers ( $h x)$ were found using:

$$
\begin{array}{r}
C_{t}=C_{0} * \text { Power }^{0.7} \\
C_{p}=C_{0} * \text { Power }^{0.8} \\
C_{h x}=C_{0} * A^{0.8}
\end{array}
$$

In order to calculate a simplified payback period (as described in an example by MAN Diesel and Turbo [23]), it is assumed that the average number of days in operation per year is 280 , the main engine fuel consumption is 180 $\mathrm{g} / \mathrm{kWh}$ [24], the power is 2 times $8900 \mathrm{~kW}$ [6] and the fuel price is $438 \mathrm{USD} /$ metric ton [25]. It is furthermore assumed that all electricity produced by the WHR system can be utilised on board the ship, where the energy system is assumed to be installed.

\section{Results and analysis}

\subsection{Governing process mechanisms}

Here we provide an analysis of the system in order to identify the governing mechanisms relevant for the process and its optimisation. Components of major influence on the process efficiency were found to be the separator, the recuperators, the boiler and the turbine.

\subsubsection{Separator}

The condensing pressure of ammonia-water mixtures is directly dependent on the ammonia concentration: ammoniarich mixtures have, at a given temperature level, relatively higher condensing pressures. For example, an ammoniawater mixture of $75 \%$ by mass at $25^{\circ} \mathrm{C}$ condenses at a pressure of 7.3 bar while pure water condenses at 0.03 bar. The outlet pressure of the turbine, and therefore the turbine power and thermal efficiency of this power cycle (Fig. 2 ), is limited by (i) the ammonia concentration at the inlet of the condenser, and (ii) the cooling water temperature. The ammonia concentration at the inlet of the condenser (6) depends on the proportion between the lean stream exiting the separation system (15) and the stream exiting the turbine (5). The main function of the separator is therefore to minimise the condensing temperature by diluting the working solution prior to the condenser (6), allowing for a lower condensation pressure and a greater turbine power output for a given cooling water temperature.

The separator must also be able to restore the working solution concentration and mass flow by supplying an ammonia-rich vapour stream, which is mixed to form the streams that enter the boiler. How the balance of these two functions strongly influences the process net power output is described further below.

The phase equilibrium and the flow rate of the solution feeding the separator govern the concentrations and mass flow rates of the output streams. The parameters affecting the equilibrium are the ammonia concentration, feed pressure and temperature. Figure 5 illustrates how the ammonia concentrations and mass flow rates of the two separator outlet streams are affected by changes in the feed stream pressure and temperature.

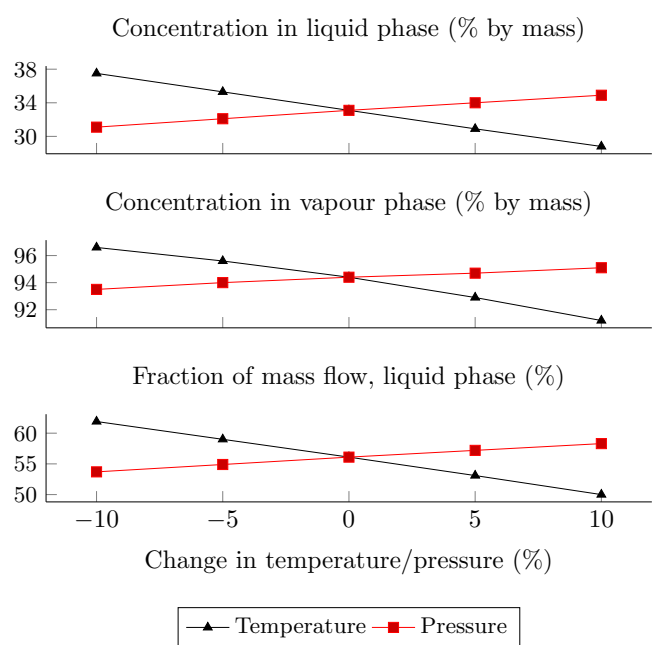

Figure 5: Trends for the separator outlet streams

The ammonia concentration at the inlet of the condenser can be regulated by adjusting the mass flow rate and/or the concentration of the lean stream exiting the separator. As Fig. 5 shows, a low concentration liquid stream can be obtained by having a combination of low pressure and high temperature. A high liquid mass flow rate can be obtained if the feed stream has a low temperature and a high pressure. Alternatively, an increased liquid outlet stream mass flow rate can be obtained by 
decreasing the feed stream concentration.

In theory, the highest power output is achieved for the minimum allowable condensing pressure, which is reached by diluting fully the working solution with the lean separator stream. However, the amount of lean liquid from the separator is limited by the amount of heat available for the feed stream to be heated sufficiently to reach the two-phase state required to support the second function of the separator, i.e. the restoration of the working solution. Therefore, the temperature and the amount of heat available from the outlet of the turbine determines how big a difference there can be between the ammonia concentrations of the condensing stream and the working solution stream.

\subsubsection{Turbine}

Figure 6 shows the calculated turbine power per $\mathrm{kg} / \mathrm{s}$ of working fluid for the ammonia concentrations from 0.72 to 0.84 and the inlet/outlet pressure ratios of $100 / 6,110 / 5$, $120 / 4$ and $130 / 3$ (bar), which are the ranges where the optimum power output of the cycle is expected to be. As shown, high turbine power outputs can be obtained by increasing the working solution ammonia concentration and also the turbine pressure ratio, for a given turbine inlet temperature $\left(330^{\circ} \mathrm{C}\right)$, and increased pressure ratios are relatively more beneficial for the turbine power output compared to changes in the solution concentration.

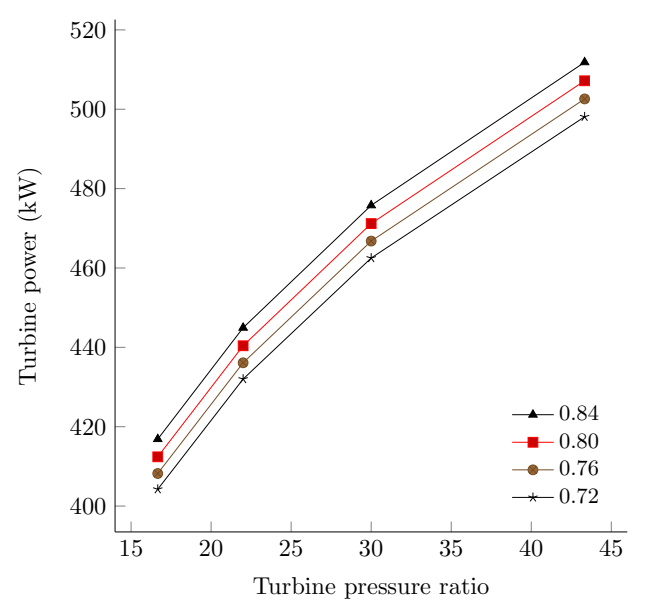

Figure 6: Turbine inlet/outlet pressure ratio influence on turbine power

Even though high turbine power outputs may be achieved by increasing the working solution concentration, this also increases the need for dilution of the condensing stream. Conversely, reducing the working solution concentration also reduces the need for dilution and/or enables lower turbine outlet pressures. The optimum performance of the cycle is therefore found at the optimum balance between the working solution concentration and the condensing stream concentration, among other factors.

\subsubsection{Split-cycle boiler}

The effect of using the Split-cycle boiler configuration with two separate streams of different concentration is illustrated in Fig. 7. It presents an example case where the working solution concentration is 0.75 and the rich stream solution concentration is varied from 0.76 to 0.92 . The rich stream ammonia concentration can, in this case, not exceed $92 \%$ (by mass) because of requirements on the cooling water temperature and because of the condensing pressure.

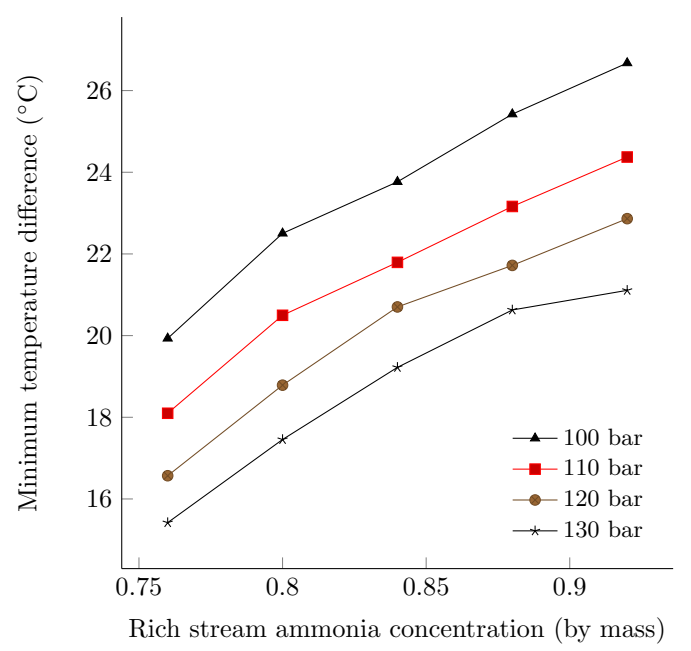

Figure 7: Rich stream composition effect on pinch point temperature difference

It can be seen how the minimum temperature difference in the first evaporator can be manipulated by varying the concentrations of the two streams. The minimum temperature difference increases with increasing rich stream concentrations, and this trend seems also to be general for a wide range of cases.

Hence, for a given pressure and working solution concentration, the pinch point temperature difference can be enlarged. This leaves room for optimising the process by changing one or a combination of the parameters, as follows: (i) lowering the ammonia concentration causes higher boiling temperatures but may enable a lower turbine expansion pressure (see section 4.1.1) which in turn will increase the net power output (Fig. 6), or (ii) the boiler pressure can be increased thus increasing turbine power output, and (iii) the boiler inlet temperature of the working fluid can be increased to get a higher average heat uptake temperature and a higher mass flow rate of the working fluid, and thus increased net power output. Alternatively, the temperature difference at the pinch point is higher, and the required heat transfer area of the boiler can be decreased.

\subsection{Optimisation results}

In the following, we present and discuss the results from applying the genetic algorithm for the optimisation of the 
Table 4: Optimum cycle performances

\begin{tabular}{rrr}
\hline & Power $(\mathrm{kW})$ & Thermal efficiency (\%) \\
\hline Kalina cycle & 1753 & 20.8 \\
Kalina cycle, reheat & 1813 & 21.5 \\
Split-cycle & 1858 & 22.1 \\
Split-cycle, reheat & 1953 & 23.2 \\
\hline
\end{tabular}

mentioned processes. Table 4 presents the respective net power outputs and thermal efficiencies. The relative gain from using reheat is more significant in the Split-cycle case process compared to the reference Kalina cycle. The Splitcycle without reheat is seen to be more efficient than the Kalina cycle with reheat. The Split-cycle process with reheat has a significantly increased power output $(+11.4 \%)$ compared to the conventional Kalina cycle.

The additional net power gained by using reheat is about $3.4 \%$ and $5.1 \%$ for the Kalina cycle and the Splitcycle. In relation to the results obtained by Bombarda et al. [6] for ORC and Kalina cycles (about $1600 \mathrm{~kW}$ net power), the optimised SC process with reheat produces about $22 \%$ more power from the same amount of heat and process boundary conditions.

All thermodynamic states of the optimised modelled cases can be found in the appendix, while Table 5 presents the optimised parameters for each investigated cycle. In the two cases with reheat, the optimum boiler pressures are lower than those of the processes without reheat. Table 5 also shows that the boiler temperature approach is lower for the Split-cycle cases, leading to higher boiler inlet temperatures compared to the regular Kalina cycle cases. The relatively higher temperatures suggest that the internal recuperation can be more effective in the Split-cycle processes, thus reducing the amount of heat rejected in the condensers.

However, there seem to be no other clear trends when comparing the remaining optimised parameters, neither when comparing the Kalina cycles and the Split-cycles, nor when comparing the cases with or without reheat. The parameters do indicate for each case the respective optimum balances between the two functions of the separator. For the Kalina cycle without reheat and the Split-cycle with reheat, the separator enables a relatively low turbine outlet pressure. This is made possible by having low concentrations of ammonia in the working solution and the separator feed streams.

Figure 8 illustrates the boiler heat transfer process in the optimised cases of the reference Kalina cycle and the Split-cycle processes with no reheat. The boiler inlet temperature of the Split-cycle is significantly higher than that of the Kalina cycle. It is clear that the Split-cycle heat transfer occurs at a higher average temperature, and a higher working fluid mass flow rate is enabled due to the smaller enthalpy difference between inlet and outlet. This would not be possible without the pinch point alteration made by the Split-cycle boiler configuration as explained in Fig. 3. The higher output of the Split-cycle compared

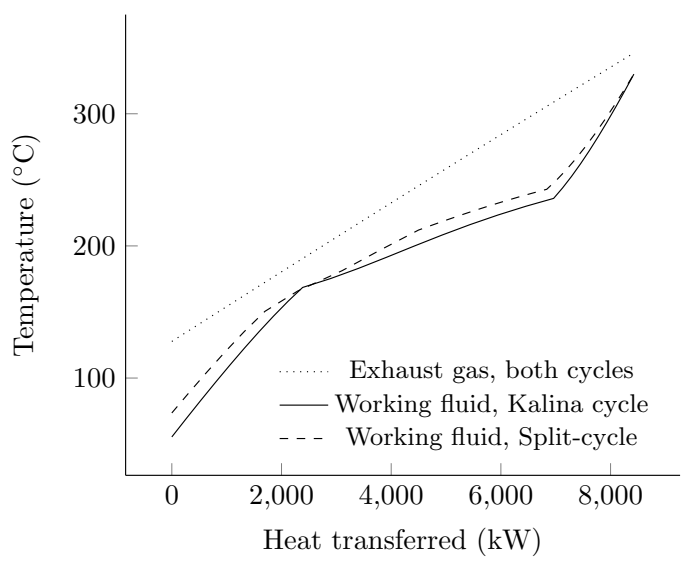

Figure 8: Heat transfer diagram

to the Kalina cycle can in this case be attributed to the higher inlet pressure of the turbine and the mass flow, since the outlet pressures and working solutions are similar.

In the two cases with reheat, the turbine mass flow rates and the turbine inlet pressures are similar. However, the turbine exhaust pressure is markedly lower in the Splitcycle case. Hence, the overall turbine pressure ratio is in this case the reason for the improved efficiency, in spite of a significantly lower working solution concentration in the $\mathrm{SC}$ case.

\subsection{Cost analysis}

The resulting heat transfer areas in all the four cycles are shown in Table 6 . The largest areas are in the boiler components due to the low heat transfer coefficients on the gas side. An increase in heat transfer areas as result of both reheat and the Split-cycle boiler is seen.

The estimated purchase cost of each of the cycles are shown in Table 7 . The boiler heat exchangers and the turbines represent in all cases about $85 \%$ of the cycle cost. While only considering the expenses for the main components and not including piping, generators, cooling system, installation and maintenance plus (possibly) the cost of the extra fuel added when the engine is tuned for WHR operation, the payback periods must be considered optimistic. In addition, in the calculation of the cycle power outputs, heat and pressure losses have not been considered. However, the results in Table 7 suggests that the Split-cycle without reheat may be a better option in terms of specific cost and payback time compared to a Kalina cycle with reheat. Furthermore, the payback times are seen to be of similar magnitude. Hence, when considering a ship lifetime of 20 years, the potential economical and environmental gains of the Split-cycle, even with reheat, seem considerable. 
Table 5: Optimised parameters

\begin{tabular}{rrrrr}
\hline & Kalina cycle & Kalina, reheat & Split-cycle & Split-cycle, reheat \\
\hline Separator feed temperature $\left({ }^{\circ} \mathrm{C}\right)$ & 86.53 & 86.5 & 81.2 & 85.8 \\
Separator feed pressure (bar) & 7.57 & 8.30 & 9.64 & 10.10 \\
Separator feed concentration & 0.473 & 0.500 & 0.512 & 0.478 \\
Working solution concentration & 0.6918 & 0.735 & 0.683 & 0.677 \\
Turbine outlet pressure (bar) & 3.34 & 3.84 & 3.42 & 2.88 \\
Reheat pressure (bar) & - & 47.3 & - & 36.6 \\
Turbine inlet pressure (bar) & 110.7 & 102.1 & 127.1 & 101.7 \\
Boiler approach ( $\left.{ }^{\circ} \mathrm{C}\right)$ & 28.12 & 26.8 & 7.6 & 5.0 \\
Rich stream concentration & - & - & 0.827 & 0.867 \\
\hline
\end{tabular}

Table 6: Estimated heat transfer areas

\begin{tabular}{|c|c|c|c|c|c|}
\hline Component & $\bar{U}\left(W /\left(m^{2} * K\right)\right)$ & Kalina $\left(m^{2}\right)$ & Kalina, reheat $\left(\mathrm{m}^{2}\right)$ & Split-cycle $\left(m^{2}\right)$ & Split-cycle, reheat $\left(\mathrm{m}^{2}\right)$ \\
\hline Recuperator 1 & 500 & 458 & 417 & 451 & 498 \\
\hline Recuperator 2 & 500 & 257 & 213 & 438 & 424 \\
\hline Recuperator 3 & 500 & 34 & 38 & 34 & 48 \\
\hline Recuperator 4 & 500 & - & - & 55 & 62 \\
\hline Preheater & 37.5 & 1663 & 1346 & - & - \\
\hline Evaporator 1 & 34 (36 for SC) & 2968 & 3186 & 4945 & 4083 \\
\hline Evaporator 2 & 28 & - & - & 1829 & 2849 \\
\hline Superheater/reheater & 21 & 972 & 1912 & 2026 & 3429 \\
\hline Condenser 1 & 1100 & 347 & 327 & 383 & 390 \\
\hline Condenser 2 & 1100 & 223 & 246 & 213 & 203 \\
\hline Total & & 6922 & 7685 & 10374 & 11986 \\
\hline
\end{tabular}

Table 7: Estimated purchase cost

\begin{tabular}{|c|c|c|c|c|}
\hline Component & Kalina cycle & Kalina, reheat & Split-cycle & Split-cycle, reheat \\
\hline Recuperator 1 & 79017 & 73345 & 78043 & 84559 \\
\hline Recuperator 2 & 49833 & 42901 & 76255 & 74382 \\
\hline Recuperator 3 & 9908 & 10749 & 9801 & 12913 \\
\hline Recuperator 4 & - & - & 14518 & 15998 \\
\hline Preheater & 221875 & 187333 & - & - \\
\hline Evaporator 1 & 352654 & 373228 & 530551 & 455157 \\
\hline Evaporator 2 & - & - & 239413 & 341296 \\
\hline Superheater/reheater & 144381 & 248066 & 259830 & 395832 \\
\hline Condenser 1 & 63336 & 60390 & 68607 & 69559 \\
\hline Condenser 2 & 44507 & 48043 & 42810 & 41317 \\
\hline Pump 1 & 5911 & 5453 & 7061 & 9199 \\
\hline Pump 2 & 39365 & 33986 & 29988 & 19792 \\
\hline Pump 3 & - & - & 23667 & 18024 \\
\hline Turbine 1 & 850434 & 321537 & 887984 & 382122 \\
\hline Turbine 2 & - & 713102 & - & 717473 \\
\hline Total cost $(U S D)$ & 1861221 & 2118132 & 2268528 & 2637623 \\
\hline Specific cost $(U S D / k W)$ & 1062 & 1251 & 1140 & 1351 \\
\hline Yearly savings (USD/year) & 928748 & 960536 & 984377 & 1034709 \\
\hline Payback time (years) & 2.00 & 2.36 & 2.15 & 2.55 \\
\hline
\end{tabular}




\section{Discussion}

With a WHR system output of about $10-11 \%$ of the main engine power, the Kalina cycles perform at a very similar level as the cascade type cycle for marine engine WHR studied by Choi et al. [4] . MAN Diesel and Turbo have presented studies of single and dual pressure steam WHR systems with an output of up to $11 \%$ of the engine power, when using an additional exhaust gas power turbine and also utilising the charge air and jacket water heat streams [1]. Compared to the ORC performance found by Bombarda et al. [6], the Kalina cycles in the present work were shown to be superior at the same boundary conditions.

In comparison with the working fluid of the steam cycle, the toxicity of ammonia-water mixtures will likely require the use of additional safety measures in the machinery rooms on board a ship. Even more so will the use of ORC working fluids, which can be seriously hazardous, especially the organic fluids. The Kalina cycle working fluid is already in use in marine cooling applications and for the reduction of NOx emissions in selective catalytic reduction installations on board. Ammonia-water mixtures are naturally occurring and have a relatively low environmental impact compared to the ORC refrigerant fluids which were investigated by Yang et al. [26], among others. Moreover, it has been shown that when considering only low hazard and environmentally friendly working fluids in ORCs, the efficiency is much lower than the thermodynamically optimum solution [27].

The simplified cost analysis showed that the payback time is very short compared to the ship lifetime. MAN Diesel and Turbo [1] estimated a payback time of 4-6 years for steam cycle WHR systems of similar complexity, which is likely to be more realistic than the 2-2.5 years found in the present study. The dual pressure steam cycle presented by MAN Diesel and Turbo is as complex as the Kalina cycle which suggests that the Kalina cycles should not be rejected due to their complexity or for economical reasons.

The component cost figures used are based on past purchase orders and experienced professional estimations [22]. The pump and turbine costs could alternatively have been estimated based partly on the working fluid properties as done by Zare et al. [28] for ORC systems. This would be useful, when considering the reheat option as the expander size and price would be affected. Since the working fluid is ammonia-water and the process is not similar to a small scale ORC, and to keep the cost analysis coherent, values from Rodriguez et al. were used.

A serious challenge for the application of the Kalina cycles may be the size of the boiler heat exchangers. The space inside a cargo ship is valuable although it is difficult to estimate the exact value. Compared to Wang et al. [8], who analysed a simple ammonia-water Rankine cycle driven by exhaust gas, the $\bar{U} \mathrm{~A}$ values found in the present study are 8-10 times larger for the Kalina cycle and even higher for the Split-cycle. Also the realisation of recu- perator 2 and evaporator 1 in the Split-cycle may present challenges. The relatively high boiler pressures could also be mentioned as a drawback in terms of cost and safety.

A simulation using the same process and parameter values as used by Bombarda et al. [6], was the starting point for this work. When applying the genetic algorithm, the optimised output was about $100 \mathrm{~kW}$ or about $6 \%$ greater. This indicates the level of the challenge of optimising the Kalina process with its relatively large number of design parameters. The additional Split-cycle components further increases the complexity of the optimisation process, suggesting that applying a multi-variable optimisation algorithm is a useful strategy. With up to nine parameters, the algorithm was first used to find the nearoptimum area and was then applied again with narrower ranges of parameter limits in an effort to find the true optimum. Still, several attempts of finding and verifying the optimum were needed.

An optimisation result found by using the genetic algorithm is not guaranteed to be the true optimum. Intermediate results during the optimisations revealed that the algorithm pursued two strategies simultaneously in the effort to maximize the power output: i) reducing the turbine exhaust pressure by also reducing the working fluid concentration and turbine inlet pressure, and ii) increasing the turbine inlet pressure and working fluid concentration. Although Table 5 presents the optimum parameters, different combinations of parameters can in fact result in almost equally high efficiencies. This explains to some degree why the trends of the optimised parameters are somewhat unclear.

In the application of WHR systems on large marine engines, the engine jacket cooling water and turbocharger charge air cooling streams may also be integrated into the Kalina Split-cycle. Based on the present analysis, we propose placing these where they will enable further dilution of the condensing stream. Depending on the temperature of the turbine exhaust, additional heat could successfully be supplied to the separator feed stream, either before or after Recuperator 1.

Theoretically, using the Split-cycle boiler technique of changing the working fluid concentration during preheating and evaporation, is not limited to the Kalina process. ORCs operating with zeotropic mixtures may benefit from splitting the working fluid streams in a similar way, and further studies on this topic are recommended based on the present findings. However, the Kalina process in the form presented here, with a separator playing the significant role as described in the analysis (Section 4.1.1), is designed specifically for the fluid properties of ammoniawater. Preliminary studies made by the present authors of the process using other fluid mixtures have so far not lead to advantages compared to ammonia-water mixtures. 


\section{Conclusion}

We investigated a unique process layout of the Kalina cycle, called the Split-cycle, and described the process model and analysed the governing mechanisms of the process. A conventional Kalina process was compared to the SC process with and without reheat.

The design parameters of the separator, turbine and boiler were found to be the most important for optimising the cycle efficiency. The analysis and results suggested that the most critical parameters for maximising the Splitcycle efficiency are the turbine exhaust pressure and the boiler inlet temperature.

A genetic algorithm was successfully applied to solve the problem of optimising the complex process using up to nine optimisation parameters. The values of the optimisation parameters and their trends were not predictable, thus confirming the need for the applied approach.

Results indicated that reheat leads to about $3.4 \%$ higher power output for the reference cycle and $5.1 \%$ for the $\mathrm{SC}$ process. The power output of the Split-cycle without reheat was found to be about $2.5 \%$ higher than that of the reference process with reheat. Compared to the reference process without reheat, the results suggested that the Split-cycle process with reheat is able to produce about $11.4 \%$ more power for the same heat source conditions.

The improved efficiency of the Split-cycles compared with the reference cycles can be attributed to low turbine exhaust pressures and higher boiler inlet temperatures. The latter is enabled by the split stream boiler configuration, and it is confirmed through a theoretical model study that the Split-cycle design presents a significant advantage, in terms of conversion efficiency, over the conventional Kalina cycle.

A simplified cost and heat exchanger analysis suggested that the boiler heat exchangers and turbines are the main contributors to the cost. It was found that with increasing process complexity and efficiency comes increased heat transfer areas and costs. The estimated payback times were found to be relatively short and of a similar magnitude for all cycles.

\section{Acknowledgements}

The authors wish to thank the Lighthouse Maritime Competence Centre (www.lighthouse.nu) for the financial support making this study possible.

Cecilia Gabrielii, Chalmers University of Technology, Gothenburg, Sweden, is acknowledged for her valuable comments and suggestions. Susan Canali is acknowledged for her proofreading assistance.

\section{References}

[1] MAN Diesel \& Turbo, Denmark . Waste Heat Recovery System (WHRS). 2012. Accessed 30/08/2013; URL www.mandieselturbo.com.
[2] Kalli J, Karvonen T, Makkonen T. Sulphur content in ships bunker fuel in 2015. Tech. Rep.; Ministry of Transport and Communications; Helsinki, Finland; 2009. Accessed 08/09/2013; URL www . jernkontoret.se.

[3] Shu G, Liang Y, Wei H, Tian H, Zhao J, Liu L. A review of waste heat recovery on two-stroke IC engine aboard ships. Renewable and Sustainable Energy Reviews 2013;19(0):385 401. doi:dx.doi.org/10.1016/j.rser.2012.11.034.

[4] Choi BC, Kim YM. Thermodynamic analysis of a dual loop heat recovery system with trilateral cycle applied to exhaust gases of internal combustion engine for propulsion of the 6800 TEU container ship. Energy 2013;58(0):404 -16. doi: dx.doi.org/10.1016/j.energy.2013.05.017.

[5] Yu G, Shu G, Tian H, Wei H, Liu L. Simulation and thermodynamic analysis of a bottoming organic rankine cycle (ORC) of diesel engine (DE). Energy 2013;51(0):281 -90. doi: dx.doi.org/10.1016/j.energy.2012.10.054.

[6] Bombarda P, Invernizzi CM, Pietra C. Heat recovery from Diesel engines: A thermodynamic comparison between Kalina and ORC cycles. Applied Thermal Engineering 2010;30(23):212-9. doi:10.1016/j.applthermaleng.2009.08.006.

[7] Jonsson M, Yan J. Exergy and Pinch Analysis of Diesel Engine Bottoming Cycles with Ammonia-Water Mixtures as Working Fluid. International Journal of Thermodynamics 2010;3(2):57-71. doi:10.5541/ijot.34. Accessed 03/10/2013; URL ehakem.com/index.php/IJoT/article/view/34.

[8] Wang J, Yan Z, Wang M, Dai Y. Thermodynamic analysis and optimization of an ammonia-water power system with LNG (liquefied natural gas) as its heat sink. Energy 2013;50(0):513 -22. doi:dx.doi.org/10.1016/j.energy.2012.11.034.

[9] Li X, Zhang Q, Li X. A Kalina cycle with ejector . Energy 2013;54(0):212 -9. doi:dx.doi.org/10.1016/j.energy.2013.03.040.

[10] Wang J, Dai Y, Gao L. Exergy analyses and parametric optimizations for different cogeneration power plants in cement industry. Applied Energy 2009;86(6):941-8. doi: 10.1016/j.apenergy.2008.09.001.

11] Kalina A. A Kalina cycle technology and its applications. American Institute of Chemical Engineers, New York, NY United States of America; 1986,Accessed 30/08/2013; URL www.osti.gov.

[12] Larsen U, Nguyen TV, Haglind F. Development of a multilevel approach to model and optimise the Kalina Split Cycle. In: Proceedings of the 53rd Scandinavian Conference on Simulation and Modeling. Orkustofnun National Energy Authority, Reykjavik, Iceland; 2012, p. 243-54. Accessed 30/08/2013; URL os.is/gogn/Skyrslur/OS-2012/0S-2012-06.pdf.

[13] Mathworks . Matlab R2010b Documentation. Tech. Rep.; Massachusetts, The United States; 2010. Accessed 26/04/2013; URL www . mathworks.se.

[14] Lemmon E, Huber M, McLinden M. NIST Standard Reference Database 23 Reference Fluid Thermodynamic and Transport Properties-REFPROP, Software Version 9.0, National Institute of Standards and Technology, Gaithersburg, United States. 2010. Accessed 30/08/2013; URL www.nist.gov/srd/nist23.cfm.

[15] Tillner-Roth R, Friend DG. A Helmholtz free energy formulation of the thermodynamic properties of the mixture \{water+ammonia\}. Journal of Physical and Chemical Reference Data 1998;27(1):63-96. doi:dx.doi.org/10.1063/1.556015.

[16] Zhang X, He M, Zhang Y. A review of research on the Kalina cycle. Renewable and Sustainable Energy Reviews 2012;16(7):5309 -18. doi:10.1016/j.rser.2012.05.040.

[17] Aspen Tech Massachusetts, USA . Aspen Plus Software Version 7.2. 2010. Accessed 01/06/2013; URL www. aspentech.com.

[18] Chipperfield A, Fleming PJ, Pohlheim H, Fonseca CM. Genetic Algorithm Toolbox for use with Matlab. Tech. Rep.; Department of Automatic Control and Systems Engineering, University of Sheffield; Sheffield, United Kingdom; 1994. doi:10.1.1.16.1178. Accessed 01/06/2013; URL Www. lasc.univ-metz.fr/IMG/pdf/GATBXA0.pdf.

[19] Rodriguez CEC, Palacio JCE, Venturini OJ, Lora EES, 
Cobas VM, dos Santos DM, et al. Exergetic and economic comparison of ORC and Kalina cycle for low temperature enhanced geothermal system in Brazil . Applied Thermal Engineering 2013;52(1):109 -19. doi: dx.doi.org/10.1016/j.applthermaleng.2012.11.012.

[20] Thorin E. Comparison of Correlations for Predicting Thermodynamic Properties of AmmoniaWater Mixtures. International Journal of Thermophysics 2000;21(4):853-70. doi: 10.1023/A:1006658107014.

21] Thorin E. Thermophysical Properties of Ammonia-Water Mixtures for Prediction of Heat Transfer Areas in Power Cycles. International Journal Of Thermophysics 2001;22(Part 1):20114.

[22] Rodriguez CEC, Palacio JCE, Venturini OJ, Lora EES, Cobas VM, dos Santos DM, et al. Exergetic and economic analysis of Kalina cycle for low temperature geothermal sources in Brazil . In: The 25th International Conference on Efficiency, Cost, Optimization, Simulation and Environmental Impact of Energy, ECOS 2012. 2012, p. $167-79$. Accessed 05/09/2013; URL www.fupress.com/archivio/pdf/5493.pdf.

[23] MAN Diesel \& Turbo, Denmark . Thermo Efficiency System for Reduction of Fuel Consumption and CO2 Emission. 2009. Accessed 05/09/2013; URL www.mandieselturbo.de.

[24] Wartsila, Helsinki, Finland. Wartsila 32, Technology Review. 2007. Accessed 05/09/2013; URL www.wartsila.com.

[25] MAN Diesel \& Turbo, Denmark . Operation on LowSulphur Fuels. 2010. Accessed 05/09/2013; URL www.mandieselturbo.com.

[26] Yang K, Zhang H, Wang Z, Zhang J, Yang F, Wang E, et al. Study of zeotropic mixtures of ORC (organic rankine cycle) under engine various operating conditions. Energy 2013;58(0):494 - 510. doi:dx.doi.org/10.1016/j.energy.2013.04.074

[27] Larsen U, Pierobon L, Haglind F, Gabrielii C. Design and optimisation of organic Rankine cycles for waste heat recovery in marine applications using the principles of natural selection. Energy 2013;55(0):803 -12. doi: dx.doi.org/10.1016/j.energy.2013.03.021.

[28] Zare V, Mahmoudi S, Yari M, Amidpour M. Thermoeconomic analysis and optimization of an ammoniawater power/cooling cogeneration cycle. Energy 2012;47(1):271 83. doi:dx.doi.org/10.1016/j.energy.2012.09.002. Asia-Pacific Forum on Renewable Energy 2011.

\section{Appendix}

Tables of state points for the cycles. Vapour quality (q) is indicated by $S U B$ when subcooled and $S U P$ when superheated. 
Table 8: State points, Kalina cycle

\begin{tabular}{rrrrrrr}
\hline & $\dot{m}(\mathrm{~kg} / \mathrm{s})$ & $T\left({ }^{\circ} \mathrm{C}\right)$ & $P($ bar $)$ & $h(\mathrm{~kJ} / \mathrm{kg})$ & $x$ & $q$ \\
\hline 1 & 3.9 & 168.6 & 110.7 & 918 & 0.692 & 0 \\
2 & 3.9 & 236 & 110.7 & 2100 & 0.692 & 1 \\
3 & 3.9 & 330 & 110.7 & 2478 & 0.692 & $\mathrm{SUP}$ \\
4 & 3.9 & 99.9 & 3.3 & 1982 & 0.692 & 0.948 \\
5 & 3.9 & 64.3 & 3.3 & 1170 & 0.692 & 0.61 \\
6 & 9.9 & 54.5 & 3.3 & 487 & 0.473 & 0.217 \\
7 & 9.9 & 30 & 3.3 & 46 & 0.473 & 0 \\
8 & 9.9 & 30.1 & 7.6 & 46 & 0.473 & SUB \\
9 & 7.8 & 30.1 & 7.6 & 46 & 0.473 & SUB \\
10 & 7.8 & 58.9 & 7.6 & 216 & 0.473 & 0.026 \\
11 & 7.8 & 83.6 & 7.6 & 621 & 0.473 & 0.227 \\
12 & 6 & 83.6 & 7.6 & 266 & 0.332 & 0 \\
13 & 1.8 & 83.6 & 7.6 & 1830 & 0.954 & 1 \\
14 & 6 & 35.1 & 7.6 & 47 & 0.332 & SUB \\
15 & 6 & 35.2 & 3.3 & 47 & 0.332 & SUB \\
16 & 1.8 & 51.5 & 7.6 & 1591 & 0.954 & 0.917 \\
17 & 2.1 & 30.1 & 7.6 & 46 & 0.473 & SUB \\
18 & 3.9 & 51.2 & 7.6 & 749 & 0.692 & 0.379 \\
19 & 3.9 & 30.2 & 7.6 & 173 & 0.692 & 0 \\
20 & 3.9 & 32.8 & 110.7 & 193 & 0.692 & SUB \\
21 & 3.9 & 55.4 & 110.7 & 302 & 0.692 & SUB \\
22 & 35 & 346 & 2 & 815 & - & - \\
23 & 35 & 308.8 & 2 & 773 & - & - \\
24 & 35 & 190.5 & 2 & 643 & - & - \\
25 & 35 & 127.7 & 2 & 574 & - & - \\
\hline & & & & & &
\end{tabular}

Table 9: State points, Kalina cycle, reheat

\begin{tabular}{rrrrrrr}
\hline & $\dot{m}(\mathrm{~kg} / \mathrm{s})$ & $T\left({ }^{\circ} \mathrm{C}\right)$ & $P($ bar $)$ & $h(\mathrm{~kJ} / \mathrm{kg})$ & $x$ & $q$ \\
\hline 1 & 3.6 & 156 & 102.1 & 884 & 0.735 & 0 \\
2 & 3.6 & 224.8 & 102.1 & 2072 & 0.735 & 1 \\
3 & 3.6 & 330 & 102.1 & 2469 & 0.735 & SUP \\
3 & 3.6 & 290.5 & 47.3 & 2338 & 0.735 & SUP \\
$3 "$ & 3.6 & 330 & 47.3 & 2549 & 0.735 & SUP \\
4 & 3.6 & 134.6 & 3.8 & 2138 & 0.735 & SUP \\
5 & 3.6 & 63.3 & 3.8 & 1226 & 0.735 & 0.651 \\
6 & 8.8 & 56.1 & 3.8 & 533 & 0.5 & 0.242 \\
7 & 8.8 & 30.1 & 3.8 & 56 & 0.5 & 0 \\
8 & 8.8 & 30.2 & 8.3 & 56 & 0.5 & SUB \\
9 & 7.1 & 30.2 & 8.3 & 56 & 0.5 & SUB \\
10 & 7.1 & 58 & 8.3 & 228 & 0.5 & 0.03 \\
11 & 7.1 & 86.5 & 8.3 & 696 & 0.5 & 0.267 \\
12 & 5.2 & 86.5 & 8.3 & 281 & 0.335 & 0 \\
13 & 1.9 & 86.5 & 8.3 & 1836 & 0.953 & 1 \\
14 & 5.2 & 35.2 & 8.3 & 47 & 0.335 & SUB \\
15 & 5.2 & 35.3 & 3.8 & 47 & 0.335 & SUB \\
16 & 1.9 & 53.1 & 8.3 & 1585 & 0.953 & 0.912 \\
17 & 1.7 & 30.2 & 8.3 & 56 & 0.5 & SUB \\
18 & 3.6 & 51.2 & 8.3 & 851 & 0.735 & 0.442 \\
19 & 3.6 & 30.2 & 8.3 & 210 & 0.735 & 0 \\
20 & 3.6 & 32.7 & 102.1 & 229 & 0.735 & SUB \\
21 & 3.6 & 59.7 & 102.1 & 359 & 0.735 & SUB \\
22 & 35 & 346 & 2 & 815 & - & - \\
23 & 35 & 289.8 & 2 & 752 & - & - \\
24 & 35 & 177.9 & 2 & 629 & - & - \\
25 & 35 & 127.7 & 2 & 574 & - & - \\
\hline & & & & & &
\end{tabular}

Table 10: State points, Split-cycle

\begin{tabular}{rrrrrrr}
\hline & \multicolumn{1}{c}{$\mathrm{m}(\mathrm{kg} / \mathrm{s})$} & $T\left({ }^{\circ} \mathrm{C}\right)$ & $P(\mathrm{bar})$ & $h(\mathrm{~kJ} / \mathrm{kg})$ & $x$ & $q$ \\
\hline 1 & 4.112 & 212 & 127.1 & 1499 & 0.683 & 0.535 \\
2 & 4.112 & 242.9 & 127.1 & 2067 & 0.683 & 1 \\
3 & 4.112 & 330 & 127.1 & 2454 & 0.683 & $\mathrm{SUP}$ \\
4 & 4.112 & 100.4 & 3.4 & 1955 & 0.683 & 0.932 \\
5 & 4.112 & 67.6 & 3.4 & 1188 & 0.683 & 0.612 \\
6 & 9.858 & 52.2 & 3.4 & 545 & 0.512 & 0.258 \\
7 & 9.858 & 25 & 3.4 & 37 & 0.512 & 0 \\
8 & 9.858 & 25.2 & 9.6 & 38 & 0.512 & $\mathrm{SUB}$ \\
9 & 9.858 & 62.5 & 9.6 & 267 & 0.512 & 0.041 \\
10 & 9.858 & 81.2 & 9.6 & 587 & 0.512 & 0.211 \\
11 & 7.78 & 81.2 & 9.6 & 263 & 0.389 & 0 \\
12 & 6.291 & 81.2 & 9.6 & 263 & 0.389 & 0 \\
13 & 5.746 & 81.2 & 9.6 & 263 & 0.389 & 0 \\
14 & 5.746 & 42.8 & 9.6 & 85 & 0.389 & $\mathrm{SUB}$ \\
15 & 5.746 & 42.9 & 3.4 & 85 & 0.389 & $\mathrm{SUB}$ \\
16 & 1.489 & 81.2 & 9.6 & 263 & 0.389 & 0 \\
17 & 0.545 & 81.2 & 9.6 & 263 & 0.389 & 0 \\
18 & 2.077 & 81.2 & 9.6 & 1803 & 0.971 & 1 \\
19 & 1.653 & 81.2 & 9.6 & 1803 & 0.971 & 1 \\
20 & 2.198 & 81.2 & 9.6 & 1421 & 0.827 & 0.752 \\
21 & 2.198 & 61.7 & 9.6 & 1227 & 0.827 & 0.667 \\
22 & 2.198 & 42.8 & 9.6 & 965 & 0.827 & 0.517 \\
23 & 2.198 & 30.1 & 9.6 & 297 & 0.827 & 0 \\
24 & 2.198 & 33.8 & 127.1 & 322 & 0.827 & $\mathrm{SUB}$ \\
25 & 2.198 & 73.6 & 127.1 & 515 & 0.827 & $\mathrm{SUB}$ \\
26 & 0.424 & 81.2 & 9.6 & 1803 & 0.971 & 1 \\
27 & 1.914 & 81.2 & 9.6 & 604 & 0.518 & 0.222 \\
28 & 1.914 & 72.6 & 9.6 & 470 & 0.518 & 0.154 \\
29 & 1.914 & 42.8 & 9.6 & 123 & 0.518 & $\mathrm{SUB}$ \\
30 & 1.914 & 45.3 & 127.1 & 144 & 0.518 & $\mathrm{SUB}$ \\
31 & 1.914 & 73.6 & 127.1 & 278 & 0.518 & $\mathrm{SUB}$ \\
32 & 1.914 & 212 & 127.1 & 1040 & 0.518 & 0 \\
33 & 2.198 & 212 & 127.1 & 1899 & 0.827 & 1 \\
34 & 35 & 346 & 2 & 815 & - & - \\
35 & 35 & 305.6 & 2 & 770 & - & - \\
36 & 35 & 245.5 & 2 & 703 & - & - \\
37 & 35 & 127.7 & 2 & 574 & - & - \\
\hline & & & & & &
\end{tabular}


Table 11: State points, Split-cycle, reheat

\begin{tabular}{rrrrrrr}
\hline & $\dot{m}(\mathrm{~kg} / \mathrm{s})$ & $T\left({ }^{\circ} \mathrm{C}\right)$ & $P(\mathrm{bar})$ & $h(\mathrm{~kJ} / \mathrm{kg})$ & $x$ & $q$ \\
\hline 1 & 3.6 & 194.8 & 101.7 & 1390 & 0.677 & 0.478 \\
2 & 3.6 & 234.9 & 101.7 & 2134 & 0.677 & 1 \\
3 & 3.6 & 330 & 101.7 & 2500 & 0.677 & $\mathrm{SUP}$ \\
3 & 3.6 & 281 & 36.6 & 2331 & 0.677 & $\mathrm{SUP}$ \\
$3 "$ & 3.6 & 330 & 36.6 & 2602 & 0.677 & $\mathrm{SUP}$ \\
4 & 3.6 & 133.1 & 2.9 & 2185 & 0.677 & $\mathrm{SUP}$ \\
5 & 3.6 & 73.4 & 2.9 & 1323 & 0.677 & 0.669 \\
6 & 10.6 & 51.3 & 2.9 & 502 & 0.478 & 0.234 \\
7 & 10.6 & 25 & 2.9 & 24 & 0.478 & 0 \\
8 & 10.6 & 25.1 & 10.1 & 25 & 0.478 & $\mathrm{SUB}$ \\
9 & 10.6 & 68.4 & 10.1 & 256 & 0.478 & 0.021 \\
10 & 10.6 & 85.8 & 10.1 & 549 & 0.478 & 0.174 \\
11 & 8.8 & 85.8 & 10.1 & 282 & 0.376 & 0 \\
12 & 7.3 & 85.8 & 10.1 & 282 & 0.376 & 0 \\
13 & 7 & 85.8 & 10.1 & 282 & 0.376 & 0 \\
14 & 7 & 41.9 & 10.1 & 79 & 0.376 & $\mathrm{SUB}$ \\
15 & 7 & 42 & 2.9 & 79 & 0.376 & 0 \\
16 & 1.5 & 85.8 & 10.1 & 282 & 0.376 & 0 \\
17 & 0.3 & 85.8 & 10.1 & 282 & 0.376 & 0 \\
18 & 1.8 & 85.8 & 10.1 & 1817 & 0.965 & 1 \\
19 & 1.4 & 85.8 & 10.1 & 1817 & 0.965 & 1 \\
20 & 1.7 & 85.8 & 10.1 & 1559 & 0.867 & 0.832 \\
21 & 1.7 & 60.3 & 10.1 & 1325 & 0.867 & 0.734 \\
22 & 1.7 & 41.9 & 10.1 & 1087 & 0.867 & 0.597 \\
23 & 1.7 & 30 & 10.1 & 337 & 0.867 & 0 \\
24 & 1.7 & 33.1 & 101.7 & 357 & 0.867 & SUB \\
25 & 1.7 & 80.8 & 101.7 & 591 & 0.867 & SUB \\
26 & 0.4 & 85.8 & 10.1 & 1817 & 0.965 & 1 \\
27 & 1.9 & 85.8 & 10.1 & 615 & 0.504 & 0.217 \\
28 & 1.9 & 74.5 & 10.1 & 439 & 0.504 & 0.128 \\
29 & 1.9 & 41.9 & 10.1 & 112 & 0.504 & SUB \\
30 & 1.9 & 43.8 & 101.7 & 129 & 0.504 & SUB \\
31 & 1.9 & 80.8 & 101.7 & 304 & 0.504 & SUB \\
32 & 1.9 & 194.8 & 101.7 & 915 & 0.504 & 0 \\
33 & 1.7 & 194.8 & 101.7 & 1909 & 0.867 & 1 \\
34 & 35 & 346 & 2 & 815 & - & - \\
35 & 35 & 287.3 & 2 & 749 & - & - \\
36 & 35 & 217.7 & 2 & 672 & - & - \\
37 & 35 & 127.7 & 2 & 574 & - & - \\
\hline & & & & & &
\end{tabular}

